\title{
Digital game-based teaching Economics in Primary School
}

\author{
Petros Skiadas $^{1}$, George Sarafoglou ${ }^{2}$ and Eleni Tsami ${ }^{3}$
}

\begin{abstract}
The aim of this study is to make economics more friendly to primary school students. Distance game-based teaching is not familiar to Greek Schools (teachers and students). This survey is an innovation for the Greek Education and makes a teaching proposal in this field. The proposal is about money and how children 6-12 years old learn to use them in their everyday life. The teaching proposal is based on the students' books of the primary school. The game-based teaching guides children to learn with fun and solve problems.
\end{abstract}

Keywords: Game-based learning, Problem-solving, Primary education, Economics.

1 Phd Student, Department of Digital Systems, University of Piraeus.

2 MSc, Department of Banking and Financial Management, University of Piraeus.

${ }^{3}$ Laboratory Teaching Staff, School of Finance and Statistics, University of Piraeus.

Article Info: Received: May 10, 2021. Revised: May 20, 2021.

Published online: June 21, 2021. 


\section{Introduction}

The aim of this study is to make economics more amicable (agreeable) to primary school students. Distance game-based teaching is not familiar to Greek Schools (teachers and students). This survey is an innovation for the Greek Education and makes a teaching proposal in this field. The proposal is about money and how children 6-12 years old learn to use it. The teaching proposal is based on the students' books of the primary school. The game-based teaching guides children to learn with fun and solve problems. Pedagogy is at the heart of teaching and learning. Preparing young people to become lifelong learners with a deep knowledge of subject matter and a broad set of social skills requires a better understanding of how pedagogy influences learning. Focusing on pedagogies shifts the perception of teachers from technicians who strive to attain the education goals set by the curriculum to experts in the art and science of teaching. (Paniagua, Al.; Istance, D., 2018).

A project named "KIDEDU" (Play Create Learn) was designed and implemented by a research team of the University of Piraeus. The proposed object is the creation of 3D animation interactive game through which children aged 6-12 years will learn "Everyday Arithmetic" in a very innovative way without the use of books, notebooks, pencils and blackboards but only with the use of sophisticated digital technology presented simply and friendly to attract children to learn indirectly through guided exploratory learning while spending their time happily. During the game, basic knowledge will be narrated and transferred, where this is deemed necessary by children, so that the voice that is heard is popular and does not refer to the voice of a teacher but to the voice of a friend or classmate. Every theory of learning is based on certain conditions and principles for the way a person learns. Every learning involves experiences and stimuli from the environment, as well as certain mental processes. So the main question for learning is what happens in relation to the stimuli of the environment and what processes happen in the mind in order to achieve learning.

The exploratory approach, as a basic principle, is supported by most educators, because it activates children and makes them participants in the learning process. The effectiveness of the discovery approach in specific circumstances has been extensively discussed. Educators and learning psychologists seem to be divided between two views: The one is learning through discovery with minimal guidance from the instructor and providing great opportunities for children to explore and experiment and the other is guided learning with carefully structured sequences of teaching steps and maximum guidance from the instructor. 


\section{Theoretical framework in Differentiated Teaching}

At all levels of education, differentiation within the classroom is an important issue. One of the biggest challenges for teachers is to meet the needs of every student in such a mixed classroom. The inability of teachers to deal with students who are at different levels of readiness does not help the school achieve its goals. Let us not forget that in recent years the number of students with learning disabilities is growing, the diagnosis of which affects all students in the class. A similar issue arises from the fact that students from different ethnicities and cultures may be in the same class. Not a small number of students transfer the problems and pressure they experience at home to school. In a learning process not all students have the same interest or find it equally attractive or fascinating, or understanding later knowledge and concepts presupposes understanding previous ones, which may not have been achieved by all students. Finally, each person has their own unique personality, is excited and inspired by different topics. Curiosity and inspiration are powerful catalysts for learning. Awareness of the problem sparks the interest of teachers to stop pretending that all students are at the same level and educate them in the same way. The differentiation of teaching and learning contributes to tackling this problem by respecting the different levels that exist in the classroom and responding to the needs of each learner.

It also demonstrates the need to create classrooms to reduce the variation of students in the above categories, making better use of teachers' knowledge for teaching and designing more equitable curricula that will utilize the skills and maximize the efficiency of each student. This way, students have more options to process and understand new information and concepts.

Differentiated teaching is not a process that should alienate the teacher. It makes sense for every teacher to feel comfortable and safe when they manage their classroom in the usual way, as well as to be afraid to apply new teaching methods, either because they can not afford to be more efficient or because they can not apply them on their own convenience, or because they fear losing control of students' behavior. All these concerns are not irrational, but we must understand that the teacher who applies differentiated teaching approaches his students better and in depth, can simultaneously monitor and manage many activities, helps and guides students individually for this reason. He gains their attention faster and exercises more control in his class and no less.

Diversified teaching is not a simple matter, it requires flexible grouping of students by each teacher. There are students who are very strong in some parts of a lesson while at the same time they are weak in others. For example, a student may be very good at math or physics problems but careless in calculations or very good at reporting but not at spelling. The teacher who uses flexible grouping also understands that sometimes it is necessary to divide students into groups and assign tasks tailored to their needs. This process varies from time to time, groups can be individual or duets, triplets and so on depending on the needs and nature of the course. 
Some educators consider asking a few students to answer more sophisticated questions orally or in writing in order to achieve differentiation. This perception is partly correct, these are strategies that are not necessarily ineffective, highlight the knowledge of such students and move in the direction of differentiation, but without covering the whole class. Others think that they differentiate their teaching by assigning more work to a few students, which is also not necessarily effective, since the large volume of work carries risks resulting in the loss of the essential purpose of the work, therefore differentiated teaching is a qualitative process and not necessarily quantitative.

Effective differentiation usually requires the teacher to plan his lesson in a variety of ways, to adapt it to each student or group of students to meet all their needs and to avoid planning with the logic of a single approach.

The teacher is constantly looking for every opportunity to get to know his students better, he observes their discussions in class, in order to form a better picture for everyone, in order to evaluate him as a whole and not through specific questions and assignments or through a competition. Evaluates students at all levels and interests. As is logical with the process these teachers based on the best awareness they have for each student can better plan the conduct of their lessons. Teaching becomes evolutionary, students and teachers are students at the same time. A necessary condition is the continuous cooperation of student-teacher. The teacher every day, every hour of teaching, understands the way students learn, recognizes what should be the relationship that connects him with each student, adapts his lesson to this pattern, so it is not forced but as a young person classroom lifestyle. Finally, differentiated teaching is a component with components of full, group and individual participation. Understanding the lesson sometimes requires the participation of all students or groups of students while other moments require the participation of individual students.

The main goal of a teacher who follows differentiated teaching is to challenge all students in the class, so that they do not get frustrated, find the motivation to learn and become active during the lesson.

\section{Learning through discovery and "guided learning"}

Learning through discovery is based on the idea that one learns something better when he discovers it on his own, rather than when one's knowledge is provided ready-made. In educational applications, learning through discovery usually takes the form of a problem to be solved, which is usually achieved by researching information and structures to find the right data. This type of learning which also has a long history in the field of video games - learning by discovery, is perhaps the key feature of numerous games and certainly all adventure games. The player reaches a point or in front of an object or in front of an enemy and does not know what to do to move forward, so he tries different solutions until he finds the right one.

Nevertheless, while learning through discovery is very effective at the level of 
electronic games and is supported by many theorists, it is likely to cause discomfort to some learners, especially those with a linear mindset and approach. At the time Paula Young and her team designed the Insider program, studying the results from the focus groups, they found that if there was a large percentage of learning in the program that came purely from personal discovery, many users tried in vain. So they came up with an interactive learning process, which they called structured discovery. Their goal was to let the player find the solution to each problem on their own, but they gave him a clear idea of exactly what the problem was to solve instead of asking him to figure it out on his own, as is the case in many video games. And of course, learning by discovery, structured or not, works better in some areas than in others.

\section{Learning based on the use of digital play for children in primary education.}

Although the hours of primary and secondary education of children with digital games are much longer than any other population group, learning based on the use of Digital Games presents a very slow penetration in our schools. While children at this age can potentially experience digital game-based learning either at home or at school, the ratio between the two is currently around 95 to 5 . At school one learns to read and write, learn to do mathematical operations and socialize. Others argue that since the future is tied to computers, knowledge of the latter is an important part of the school curriculum, but they make few references to games. Only a few have claimed that electronic games are a very strong motivator for children and it would be irrational not to use it at school.

One of the biggest problems with IT education in schools is the lack of time for practice. Therefore, the best way to improve computer education in schools is not to do it at school but at home.

-In order for children to use home education programs, the latter must outperform other activities that attract children - such as television and video games - because when they are at home, children can choose whether to engage in them. With them, while at school one can force them to deal with them.

-In order for the child to devote time to their education at home, the program should be fun, a thought that led them to the idea of giving the program the form of a video game and introducing stories and characters that interest the children.

\section{KIDEDU project}

A project named "KIDEDU" (Play Create Learn) designed and implemented by a research team of the University of Piraeus. The proposed object is the creation of 3D animation interactive game through which children aged 6-12 years will learn "Everyday Arithmetic" in a very innovative way without the use of books, notebooks, pencils and blackboards but only with the use of sophisticated digital technology presented simply and friendly to attract children to learn indirectly 
through guided exploratory learning while spending their time happily. During the game, basic knowledge will be narrated and transferred, where this is deemed necessary by children, so that the voice that is heard is popular and does not refer to the voice of a teacher but to the voice of a friend or classmate. Every theory of learning is based on certain conditions and principles for the way a person learns. Every learning involves experiences and stimuli from the environment, as well as certain mental processes. So the main question for learning is what happens in relation to the stimuli of the environment and what processes happen in the mind in order to achieve learning.

The exploratory approach, as a basic principle, is supported by most educators, because it activates children and makes them participants in the learning process. The effectiveness of the discovery approach in specific circumstances has been extensively discussed. Educators and learning psychologists seem to be divided between two views: For learning through discovery with minimal guidance from the instructor and providing great opportunities for children to explore and experiment and for guided learning with carefully structured sequences of teaching steps and maximum guidance from the instructor.

\section{Learning based on the use of digital play. The Money Subject}

One of the sections of the everyday arithmetic, as well as its goals, according to the level of knowledge that children aged 6-12 (Primary School students) should have is the following: Money-Applications.

The goals are:

- Know the currency of Euro and its subdivisions.

- Manage Euro coins to solve everyday problems.

- Correspond monetary amounts with values that are decimal numbers.

- Calculate the "change" with the help of complex problems.

- Calculate the financial cost in relation to gasoline consumption.

Indicatively we mention that: in the B primary school they are taught "I know the euro coins better, in the canteen "and" I'm counting the change, in the market". In D primary school are taught "Coins and Decimals" Banknotes Petros (a child) in the Supermarket and in the bookstore". In the 6th grade, they are taught to measure value with money (Table 1). 
Table 1: EXISTING GAMES

\begin{tabular}{|c|c|c|}
\hline $\begin{array}{c}\text { University } \\
\text { Management - "Virtual } \\
\text { U" (Management } \\
\text { Education) }\end{array}$ & $\begin{array}{c}\text { A game that concerns the } \\
\text { administration of a University. }\end{array}$ & http://www.virtual-u.org/ \\
\hline $\begin{array}{c}\text { The Stock Market } \\
\text { Game }\end{array}$ & $\begin{array}{c}\text { A game that students are required to } \\
\text { invest (hypothetically) } \$ 100,000 .\end{array}$ & http://www.smgww.org/ \\
\hline Gazillionaire & $\begin{array}{c}\text { Gazillionaire is a strategy game in } \\
\text { which the player tries to make as } \\
\text { much money as possible by buying } \\
\text { and selling space goods on exotic } \\
\text { planets. }\end{array}$ & http://www.lavamind.com/index.html \\
\hline $\begin{array}{c}\text { World Game of } \\
\text { Economics }\end{array}$ & $\begin{array}{c}\text { A game in which each student plays } \\
\text { the role of a country and tries to } \\
\text { make the right decisions to improve } \\
\text { some economic indicators. }\end{array}$ & $\mathrm{http://www.worldgameofeconomics.com/}$ \\
\hline
\end{tabular}

None of the existing games are aimed at primary school children aged 6-12 with an educational character and the use of 3D technologies. This teaching proposal is an innovation and therefore if it is adopted by teachers, it will commence a new beginning in education in Primary Schools but also at other levels of education.

This is a sample of the game. The hero is a child 9 years old (boy or girl) and the child must pass the tests so that he can leave his home and continue his/her trip. $\mathrm{He} / \mathrm{she}$ counts his/her money and answers some questions. We observe a conversation with his/her mother in the living room. The following photo (1) is a photo of the hero's living room. 


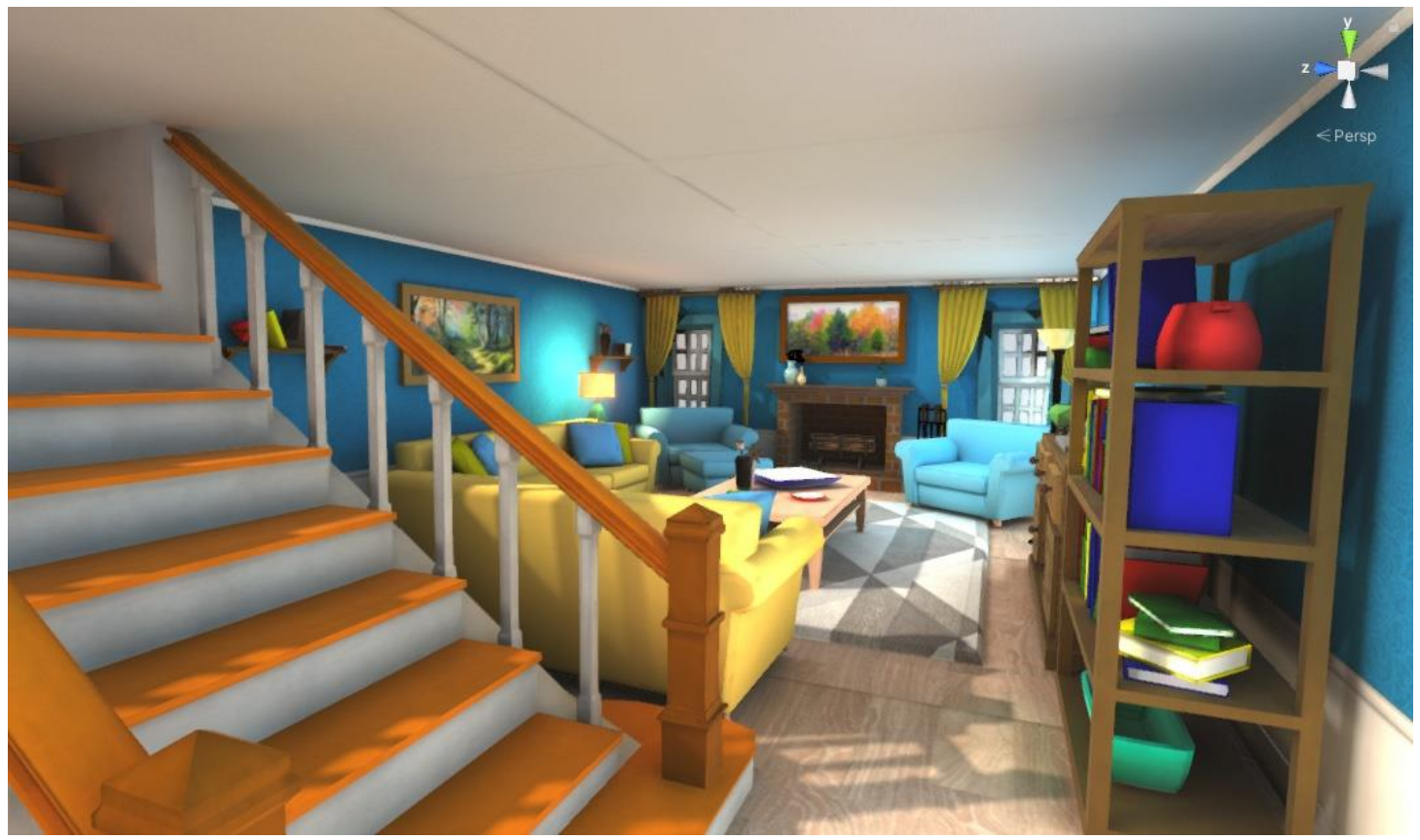

Photo 1: Hero's Living Room

Hero: It's time to dump my piggy bank to count my mates. How many students do I need to get a skate material? I will make one separately with the banknotes and items I have gathered the required in the required in the correct photos of my money.
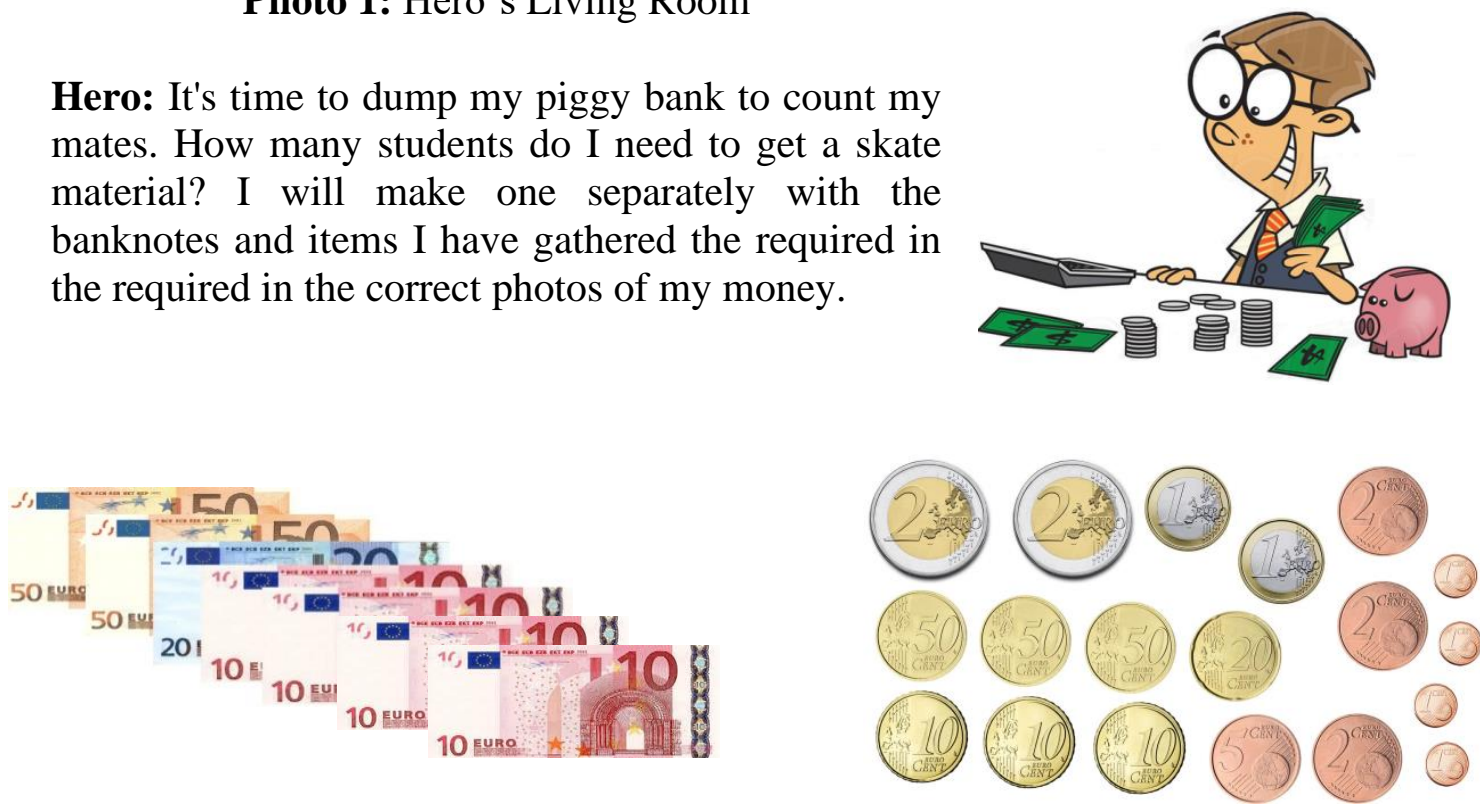

euros, from the banknotes euros, from coins so I have ............................ euros to my piggy bank. 
Hero: The skate costs $200 €$ so I miss ........euros.

Hero: I get pocket money 5 (1)

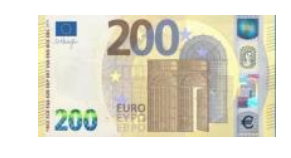

In ........days I will have collected the rest of the money I need Perfect, in a short time I will have my own skate.

Mother: What are you doing there?

Hero: I'm counting my money.

Mother: Well done my child you are doing well. Because I see you have a lot of small banknotes and coins while I have high value banknotes, do you want to exchange some?

Hero: Sure thank you mom.

Mother: I'll give you one

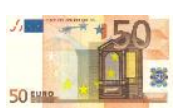

Hero: And I'll give you

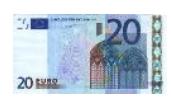
and



Mother: I can take and some coins. I'm giving you this

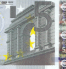
and please give me coins for 2 euros, 1 euro and 50, 20, 10 cents.

Hero: I think I have to give you ..... 2 euro coins, ...... 1 euro coins , ... 50 cents coins, .....20 cents coins, ...... 10 cents coins.

After this, the hero goes out of his/her home and starts the trip. The photo is from the hero's neighborhood. 


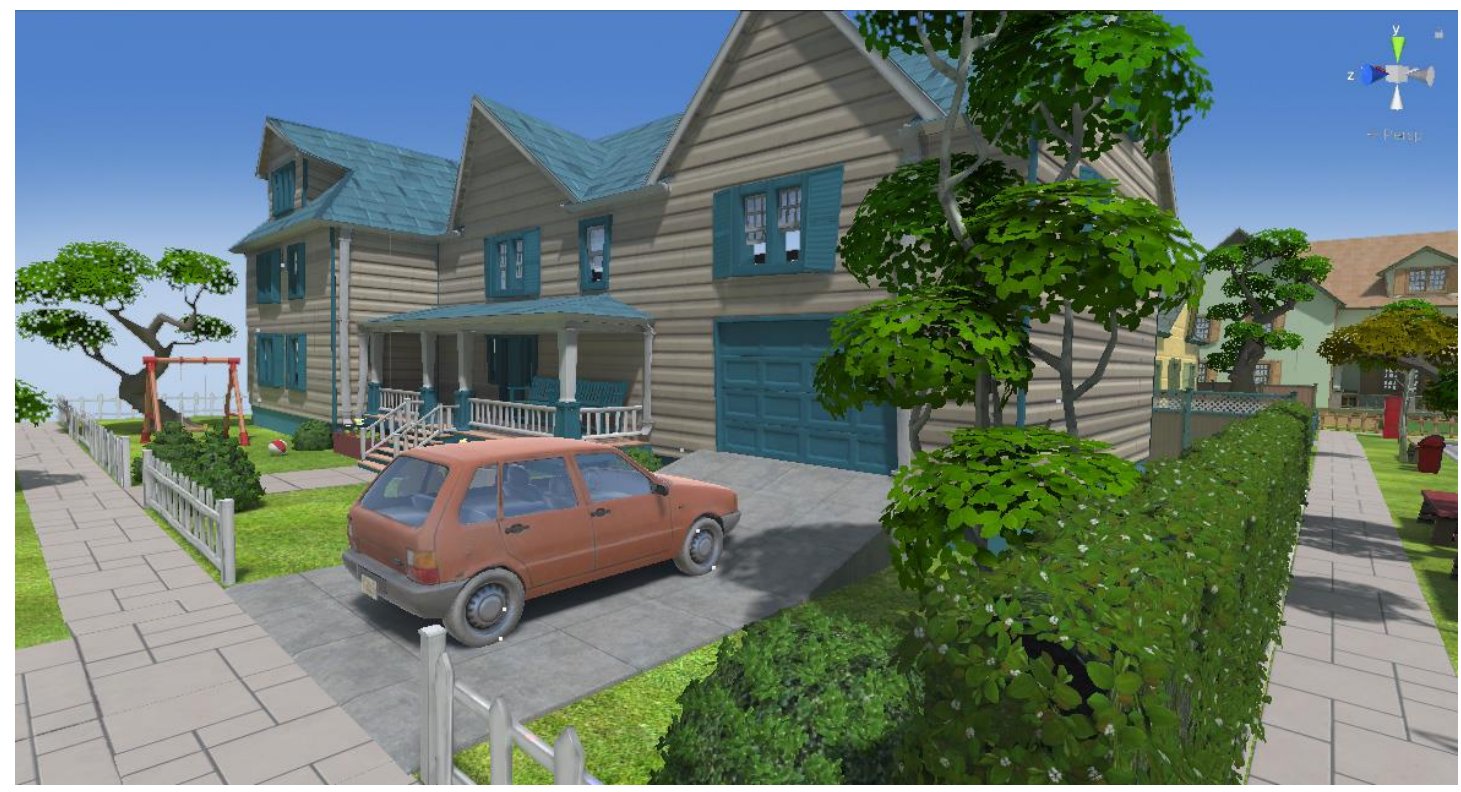

Photo 2: The hero's neighborhood.

\section{Conclusion and Discussion}

Starting with very humble efforts, digital game-based learning applications quickly penetrated all levels of childhood and student life, targeting preschoolers to graduate students. Surely one can criticize the design, the methods, the means, and even the motivations of the creators of these applications and many do. The point, however, is that this is how 21st century children grow up. Even if we wanted to, we could not go back in time or stop or prevent change. The point is not to take our children away from computers - if they really want to be there, they will find a way to do it even behind our backs - but to try to make their engagement creative. This is something completely different from television, where the means of production were very expensive and control was concentrated in the hands of very few. As we all realize - including children and teachers - creating educational examples based on digital play makes learning enjoyable. The children, together with their teachers, have already started implementing pilot programs. Our task is to encourage them, to work with them and to help them combine their new learning style with what we know about learning and life.

Educational software development is at a very early stage in Greece. The rigid educational system along with the insufficient teacher training in new technologies make the task of incorporating new software applications in the teaching process difficult. Both aspects of new technologies use in economic pedagogy provide a real increase in the quality of education. The results of this study suggest beneficial effects of implementing new technologies' enhancements. Clarity in presentation, along with enthusiasm and respect towards student views had the greatest positive 
influence on lesson evaluation by students. On the way, teachers tend to underestimate significantly these two factors and overestimate the importance of being well prepared for the lesson and knowing their subject-matter.

Students' effort plays a key role to obtaining high grades. Students claiming to have tried harder at a module acquired higher grades. Thus, we could support that tension and the total amount of time spent on studying affects the learning of Economics. Teaching assisted by games and computers is almost as effective as conventional teaching but probably costs more. Computer based study systems appear to be more effective than game and simulations especially for students of weaker performance. Educational programmes are effective because students can reach a standard level of qualification sufficiency in less time, but students are not very fond of them. Students enjoy being taught according to their personal style and this increases performance in some cases. In general research results show that the advantages of applying the use of computers in teaching economic modules are controversial. The size of the class little affects performance. However, some researches have discovered that larger classes can have negative effects in some economic fields and may influence financial benefits from education. According to Blinder the issue is of great importance and further research is required. Students prefer computer-based lessons over traditional lessons to a very high percentage.

\section{References}

[1] Serkan Çankayaa, Ayúen Karameteb, (2009). The effects of educational computer games on students' attitudes towards mathematics course and educational computer games, Procedia Social and Behavioral Sciences 1 145-149.

[2] Tom Lowrie, Robyn Jorgensen (2011). Gender differences in students' mathematics game playing, Computers \& Education, 2244-2248.

[3] Serkan Coútua, Serhat Aydınb, Mehmet Filiz, Students' conceptions about browser-game-based learning in mathematics education: TTNetvitamin case Procedia Social and Behavioral Sciences 1 (2009) 145-149.

[4] Paniagua, Alejandro, Istance, David (2018). Teachers as Designers of Learning Environments: The Importance of Innovative Pedagogies. Educational Research and Innovation OECD Publishing.

[5] Marc Prensky, Digital Game-Based Learning (2001). 